\title{
RESEARCH NOTE EPHEMERA STRIGATA IMAGOES ARE THE LIKELY SOURCE OF A PARASITIC NEMATODE INFECTION OF FISH
}

\author{
Riyo Hirasawa and Masahide Yuma
}

Center for Ecological Research, Kyoto University, Otsuka, Hirano-cho, Kami-tanakami, Otsu 520-2113, Japan

The dark chub, Zacco temmincki (Temminck et Schlegel), is the principal definitive host of the nematode Rhabdochona denudata honshuensis Moravec et Nagasawa, 1989 (Spirurida: Thelazioidea: Rhabdochonidae) in the upper reaches of the Takami River in the western part of Honshu, which is the main island of Japan (Mori T., Urabe M., Nagoshi M. 1998: Biol. Inl. Wat. 13: 67-70). The intermediate host is the nymph of the sand-burrowing mayfly Ephemera strigata Eaton (Insecta: Ephemeroptera) (Hirasawa R., Urabe M. 2003: J. Parasitol. 89: 617-620). For nematode transmission from the intermediate host to the definitive host, the definitive host fish must prey on the mayfly. However, E. strigata nymphs are not the main prey of $Z$. temmincki (Hirasawa et al. unpubl.). Furthermore, the definitive host, Z. temmincki, is not a benthic predator, but is a swimmer that feeds mainly on insects that fall on the water surface and drift with the current (Katano O. 1987: Physiol. Ecol. Jpn. 24: 1-132). Since the microhabitats of the intermediate and definitive hosts differ dramatically, there is the question of how $R$. denudata honshuensis is transmitted from the intermediate host to the definitive host. To solve this, we postulated that, in addition to a route from aquatic nymphs, the nematode is also transmitted via terrestrial imagoes.

To confirm that imagoes are potential intermediate hosts of the nematode, the prevalence and mean intensity of infection in nymphs were compared with those in imagoes. Secondly, we investigated the potential of dead imagoes as an infection source, since imagoes often drop on streams after mating and oviposition late in the evening. We also determined the survival of nematodes in the body of the dead host.

The presence of nematode larvae in the body of the intermediate host, particularly in heavily infected hosts, has a pathogenic effect, sometimes leading to the death of the host (Moravec F. 1976: Folia Parasitol. 23: 309-320). However, mayfly nymphs infected with small numbers of Rhabdochona phoxini Moravec, 1968 larvae still undergo metamorphosis and the imagoes are capable of flight (Moravec F. 1972: Folia Parasitol. 19: 321-333; 1976, op. cit.; 1977: Folia Parasitol. 24: 97-105). In the case of another fish gastrointestinal parasite, Cystidicoloides ephemeridarum (Linstow, 1872) (Spirurida: Habronematoidea: Cystidicolidae), mayfly nymphs are killed by massive infections, while smaller numbers do not prevent metamorphosis of the host (Moravec F. 1971a: Věst. Čs. Spol. Zool. 35: 43-55; 1971b: Folia Parasitol. 18: 107112). Moravec emphasized the significance of this survival in mayfly imagoes for the infection of the definitive host trout in spring and summer, when the fish feeds mostly on mayfly imagoes.
In our study locality, E. strigata has a univoltine life cycle, and the subimagoes emerge in May (Ban R., Kawai T. 1986: Aquat. Insects 8: 207-216). To compare the prevalence and intensity of nematode infection in aquatic nymphs and terrestrial imagoes, mayflies were collected in a mountain stream of the Takami River $\left(34^{\circ} 23^{\prime} \mathrm{N}, 135^{\circ} 59^{\prime} \mathrm{E}\right)$ in Japan on April 26 and May 10, 1996 and April 13 and May 5, 1997. Late-instar nymphs of E. strigata were collected using a hand net (mesh size: $1 \mathrm{~mm}$ ) in April, and flying imagoes (both male and female) were caught with an insect net in May. The collected mayflies were fixed in $70 \%$ ethanol and dissected, and the encapsulated infective nematodes (third- and fourthstage larvae) were counted. The prevalence (percentage of mayflies infected) and mean intensity (mean number of nematodes per infected mayfly) were calculated. Fisher's exact test was used to compare the prevalence, and the MannWhitney test was used to compare the intensity. In this study, we counted only third- and fourth-stage infective larval nematodes, which are easily found and identified.

Table 1 shows the prevalence and mean intensity of infective larvae of $R$. denudata honshuensis in E. strigata nymphs and imagoes. There was no significant difference in the prevalence or mean intensity between nymphs and imagoes, except for the prevalence in 1996 (1996: prevalence, $\chi^{2}=5.48$, df $=$ $1, p=0.042$; mean intensity, $\mathrm{U}=91.00, p=0.051$. 1997: prevalence, $\chi^{2}=0.17, \mathrm{df}=1, p=0.771$; mean intensity, $\mathrm{U}=$ $90.0, p=0.059$.). In 1996, the prevalence of the nematode was significantly higher in imagoes than in nymphs. In this study, the abundance of third- and fourth-stage larval $R$. denudata honshuensis in E. strigata imagoes, which were swarming and flying upstream, was similar to that in late-instar nymphs. This indicates that $R$. denudata honshuensis larvae in a mayfly nymph do not prevent its metamorphosis and mating behaviour. Consequently, E. strigata imagoes can serve as the intermediate host of $R$. denudata honshuensis, as well as nymphs.

The morning following E. strigata flights (swarming and upstream flights for mating), many dead E. strigata imagoes were observed on the surface of river pools. The dead imagoes were collected in the morning of May 6, 1997 to confirm whether the nematodes in them were still alive, as judged by nematode movement after removing them from the dead hosts. Living nematodes were found in dead mayfly imagoes $(n=4$, prevalence $100 \%$, mean intensity 4.5 , nematode survival rate $89 \%)$.

To determine the survival period of nematode larvae in a dead imago, flying mayflies were caught with an insect net in the evening of April 2, 2002. Each imago was put in a plastic Petri dish separately and kept in the dark at $13-15^{\circ} \mathrm{C}$ and 
Table 1. Comparison of the prevalence and intensity of nematode infections in Ephemera strigata nymphs and imagoes.

\begin{tabular}{|c|c|c|c|c|c|}
\hline Date & $\begin{array}{c}\text { No. of E. strigata } \\
\text { examined }\end{array}$ & $\begin{array}{c}\text { No. of E. strigata } \\
\text { infected }\end{array}$ & $\begin{array}{c}\text { Prevalence } \\
\%\end{array}$ & Mean intensity & $\begin{array}{c}\text { Intensity } \\
\text { range }\end{array}$ \\
\hline 1996 Apr. 26, nymph & 22 & 13 & $59 *$ & 3.08 n.s. & $1-12$ \\
May 10, imago & 26 & 23 & 88 & 5.17 & $1-15$ \\
1997 Apr. 13, nymph & 45 & 29 & 64 n.s. & 2.48 n.s. & $1-6$ \\
May 5, imago & 17 & 10 & 59 & 1.40 & $1-3$ \\
\hline
\end{tabular}

* Significant differences between nymph and imago within a year $(p<0.05$; prevalence, Fisher's exact test; intensity, MannWhitney U-test); n.s. not significant.

Table 2. Prevalence and mean intensity of Rhabdochona denudata honshuensis (both living and dead) infection in Ephemera strigata imagoes.

\begin{tabular}{|l|c|c|c|c|c|c|c|c|}
\hline Days after host death & 0 & 1 & 2 & 3 & 5 & 7 & 11 & 16 \\
\hline No. of E. strigata examined & 4 & 7 & 6 & 4 & 4 & 4 & 7 & 4 \\
Prevalence (\%) & 100 & 100 & 100 & 75 & 100 & 100 & 85.7 & 75 \\
Mean intensity & 17.8 & 11.9 & 9.2 & 36.0 & 5.3 & 10.0 & 3.8 & 4.7 \\
\hline
\end{tabular}

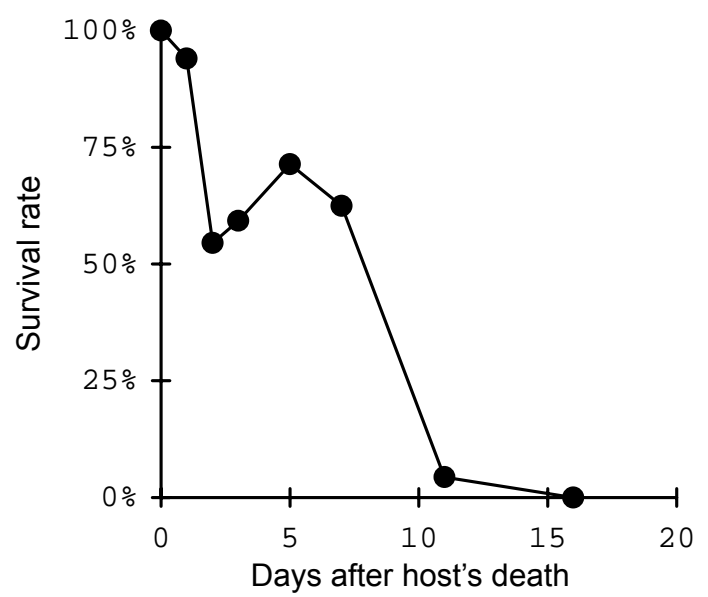

Fig. 1. Change in the survival rate of nematodes in dead Ephemera strigata imagoes.

$100 \%$ humidity. All the imagoes in the dishes were dead the next morning. The numbers of living and dead nematodes were counted every day or every other day by dissecting the

Received 23 May 2003 dead imagoes. The prevalence and mean intensity of both living and dead nematodes did not differ between experiment days (prevalence, $\chi^{2}=5.48, \mathrm{df}=7, p=0.556$ n.s.; mean intensity, ANOVA; $\mathrm{F}=(7,28) 1.03, p=0.433$ n.s.) (Table 2). Fig. 1 shows the change in the survival rate of nematodes in dead E. strigata imagoes. Over $50 \%$ of the nematodes were still alive in the intermediate hosts seven days after the death of the host. This implies that the dead imagoes can still infect Z. temmincki.

The transmission of parasitic nematodes to fish is thought to occur when fish feed on aquatic nymphs. Although mayflies spend most of their lives in an aquatic environment, it is likely that terrestrial imagoes (both living and dead) are important for transmission to fish, and this should be considered in research on the life cycles of parasitic nematodes.

Acknowledgements. We would like to thank Dr. M. Urabe in Fukuoka University of Education for helpful comments and constant support. This work was partly supported by the MEXT Grant-in-Aid for the 21st Century COE Program (A2 to Kyoto University).

Accepted 18 June 2003 